\title{
Prevalence and risk factors of abnormal left ventricular geometrical patterns in untreated hypertensive patients
}

\author{
Hui Li', Fei Pei ${ }^{3}$, Liying Shao', Jingzhou Chen², Kai Sun², Xinyu Zhang ${ }^{2}$, Channa Zhang ${ }^{2}$, Jibing Liu², \\ Chuanshi Xiao ${ }^{1 *}$ and Rutai Hui ${ }^{2^{*}}$
}

\begin{abstract}
Background: The various prevalence of LVH and abnormal LV geometry have been reported in different populations. So far, only a few reports are available on the prevalence of LV geometric patterns in a large Chinese untreated hypertensive population.

Methods: A total of 9,286 subjects (5167 men and 4119 women) completed the survey and 1641 untreated hypertensive patients (1044 males and 597 females) enrolled in the present study. The LV geometry was classified into four patterns: normal; abnormal,defined as concentric remodeling;concentric or eccentric hypertrophy based on the values of left ventricular mass index (LVMI) and relative wall thickness (RWT). Logistic regression model was applied to determine the odds ratio $(O R)$ and $95 \%$ confidence intervals $(C l)$ of the risk factors of left ventricular hypertrophy.
\end{abstract}

Results: The prevalence of LVH was $20.2 \%$ in untreated hypertensive patients, much higher in women (30.8\%) than in men $(14.2 \%)(P<0.01)$. The prevalence of LV geometrical patterns was 34.9\%, 11.1\%, 9.1\% for concentric remodeling, concentric and eccentric hypertrophy,respectively. After adjustment by using Logistic regression model, the risk factors for LVH and abnormal LV geometry were age, female, systolic blood pressure, and body mass index. And low high density lipoprotein maybe a positive factor.

Conclusions: The prevalence of LVH and abnormal LV geometric patterns was higher in women than in men and increased with age. It is crucial to improve the awareness rate of hypertension and control the risk factors of CV complications in untreated hypertensive population.

Keywords: Left ventricular hypertrophy, Left ventricular geometry, Risk factors, Untreated hypertension

\section{Background}

In hypertensive patients, an adaptive myocardial response to increased cardiac afterload results in left ventricular hypertrophy (LVH) [1]. Hypertensive LVH is a powerful independent predictor for sudden cardiac death [2], ventricular arrhythmias [3], myocardial ischemia [4],

\footnotetext{
* Correspondence: ganxibaozhongxin@sina.com; huirutai@gmail.com 'Department of Cardiology, The First Hospital Affiliated to Shanxi Medical University, 85 Jiefang South Road, Taiyuan City, Shanxi Province 030001, China

${ }^{2}$ Sino-German Laboratory for Molecular Medicine, State Key Laboratory of Cardiovascular Disease, Fuwai Hospital, National Center for Cardiovascular Diseases, Chinese Academy of Medical Sciences and Peking Union Medical College, 167 Beilishilu, Beijing 100037, China

Full list of author information is available at the end of the article
}

coronary heart disease [5], heart failure [6], as well as ischemic stroke [7].

Echocardiography is more sensitive and specific than electrocardiography in the detection of LVH [8]. Classification of patients based on whether left ventricular mass index (LVMI) and relative wall thickness (RWT) are normal or abnormal yields four left ventricular (LV) geometric patterns: normal, concentric remodeling, concentric hypertrophy and eccentric hypertrophy [9]. Previous studies have reported that echocardiographically determined LV geometry can independently predict major cardiovascular events [10], and the worst is concentric hypertrophy, followed by eccentric hypertrophy, concentric remodeling and normal 
geometry [11]. In addition, LV geometric pattern is closely related to stroke risk [12].

The various prevalence of LVH and abnormal LV geometry have been reported in different populations $[13,14]$. So far, only a few reports are available on the prevalence of LV geometric patterns in a large Chinese untreated hypertensive population. Therefore, we conducted a crosssectional study to survey the prevalence of LVH and LV geometric patterns in untreated hypertension population in northern China.

\section{Methods}

\section{Study population}

This community-based cross-sectional study was conducted in the Rizhao City and Hong Xing Long County, in the northern region of China from 2009 to 2010. A multistage cluster sampling method was used. A total of 9,286 subjects (5167 men and 4119 women) completed the survey, yielding a response rate of $97.48 \%$. Among them, 2984 hypertensive patients were identified and thoroughly examined. Hypertension was defined as diastolic blood pressure (DBP) of $\geq 90 \mathrm{mmHg}$, and/or systolic blood pressure (SBP) of $\geq 140 \mathrm{mmHg}$, physician diagnosis, or current medication for hypertension (as defined by WHO 1999). Untreated hypertension was defined as never receiving any antihypertensive treatment befor the study.

Patients were excluded if they had hypertrophic cardiomyopathy, ischemic heart disease, congenital heart disease, or other organic heart disease including valvular disease. Patients with secondary hypertension, either suspected or established, were excluded as well.

The study was governed under the most recent (2007-2008) version of the World Medical Association's Declaration of Helsinki. The study protocol was reviewed and approved by the ethical committees of the Fuwai Hospital and local hospitals. Participation is voluntary; informed consent was obtained from each participant. All investigators were trained at the Cardiovascular Institute, Chinese Academy of Medical Sciences (Beijing, China) and qualified for the clinical investigation.

\section{Data collection}

We identified eligible individuals according to their age and documents of residence and invited them to a community clinic by telephone. Each participant was interviewed and completed a standardized questionnaire that included a range of demographic factors, medical history, history of medications, and lifestyle.

\section{Physical examination}

Anthropometric measurements of subjects who wore light clothing and were in bare feet were conducted by experienced research staff. Height was measured once to the nearest $0.1 \mathrm{~cm}$, and weight was measured in the upright position to the nearest $0.1 \mathrm{~kg}$.

BP was measured by trained professionals with a standardized mercury sphygmomanometer, and one of three cuff sizes (regular adult, large, or small) was chosen on the basis of the circumference of the participant's right arm. All participants were advised to avoid alcohol, cigarette smoking, coffee/tea, and exercise for at least 30 minutes before their BP measurement. Three BP readings were recorded at least 1 minute apart in the sitting position after at least 5-minute rest and averaged for further analysis.

\section{Echocardiography}

Transthoracic echocardiography was performed according to standard protocol [15] with M-mode, 2dimensional (2D), and color Doppler recordings from the parasternal long-axis and short-axis windows, as well as 2D and color Doppler evaluations from the apical window to yield 2-, 3-, and 4-chamber images with an HP 5500 (Phillips Medical System, Boston, Massachusetts, USA). The transducer frequency was 2.5 to $3.5 \mathrm{MHz}$. Optigo echocardiographic recorders (Agilent, Boston, Massachusetts, USA) were used occasionally to screen subjects who could not reach the local study center. The echocardiographic examination was supervised by 2 physician-echocardiographers with at least 2 years of experience. Before the study, they were trained in the echocardiographic protocol at the Cardiovascular Institute, Chinese Academy of Medical Sciences.

\section{Calculation of derived variables}

Left ventricular mass (LVM) was calculated using the equation:

LVM $=0.8 \times 1.04 \times\left[(\text { IVSd }+ \text { LVIDD }+ \text { PWTd })^{3}-\right.$ LVIDD $\left.^{3}\right]+0.6$, which yields values closely related $(R=$ $0.90)$ to necropsy LV weight [16], where IVSd is septal wall thickness at end diastole, PWTd is posterior wall thickness at end diastole, and LVIDD is left ventricular end-diastolic diameter.

LVM was divided by height ${ }^{2.7}$ and body surface area (BSA) to obtain left ventricular mass index ( $\mathrm{LVMI}_{\mathrm{h} 2.7}$ and LVMI $_{\text {BSA }}$ ). BSA was calculated by using the Du Bois formula [17]: $0.0071843 \times(\text { weight }(\mathrm{kg}))^{0.4253} \times(\text { height }(\mathrm{cm}))^{0.725}$.

LV hypertrophy was diagnosed by using the criteria of the LVMI $_{\mathrm{h} 2.7}$ more than $49.2 \mathrm{~g} / \mathrm{m}^{2.7}$ and $46.7 \mathrm{~g} / \mathrm{m}^{2.7}$ for males and females, respectively [18]. Relative wall thickness (RWT) [19] was calculated by $2 \times$ PWTd/LVIDD.

The LV geometry was classified into four patterns based on LVMI and RWT [20] values:

(1) Normal geometry: LVMI was normal and RWT was $<0.43$;

(2) Concentric hypertrophy: LVMI was increased and RWT was $\geq 0.43$; 
Table 1 Clinical characteristics of 1641 untreated hypertensive patients

\begin{tabular}{|c|c|c|c|c|}
\hline Variables & Whole group $(n=1641)$ & Male $(n=1044)$ & Female $(n=597)$ & $\mathrm{p}$ value \\
\hline Age (years) & $50.4 \pm 12.18$ & $47.8 \pm 12.26$ & $55.1 \pm 10.53$ & $<0.001$ \\
\hline Height $(\mathrm{cm})$ & $165.6 \pm 8.76$ & $170.3 \pm 6.47$ & $157.5 \pm 5.90$ & $<0.001$ \\
\hline Weight (kg) & $73.5 \pm 12.97$ & $78.7 \pm 11.76$ & $65.6 \pm 9.75$ & $<0.001$ \\
\hline BMI $\left(\mathrm{kg} / \mathrm{m}^{2}\right)$ & $26.7 \pm 3.38$ & $27.1 \pm 3.28$ & $26.0 \pm 3.50$ & $<0.001$ \\
\hline BSA $\left(m^{2}\right)$ & $1.8 \pm 0.19$ & $1.9 \pm 0.16$ & $1.7 \pm 0.13$ & $<0.001$ \\
\hline $\mathrm{SBP}(\mathrm{mmHg})$ & $139.5 \pm 15.29$ & $138.8 \pm 14.69$ & $140.7 \pm 16.23$ & 0.013 \\
\hline $\mathrm{DBP}(\mathrm{mmHg})$ & $92.0 \pm 9.34$ & $93.7 \pm 8.83$ & $88.9 \pm 9.43$ & $<0.001$ \\
\hline $\mathrm{PP}(\mathrm{mmHg})$ & $47.5 \pm 15.52$ & $45.1 \pm 14.19$ & $51.8 \pm 16.79$ & $<0.001$ \\
\hline MAP $(\mathrm{mmHg})$ & $107.8 \pm 9.09$ & $108.7 \pm 8.90$ & $106.2 \pm 9.19$ & $<0.001$ \\
\hline Plasma glucose (mmol/L) & $5.5 \pm 1.86$ & $5.4 \pm 1.98$ & $5.7 \pm 1.59$ & $<0.001$ \\
\hline Cholesterol (mmol/L) & $5.4 \pm 1.05$ & $5.5 \pm 1.05$ & $5.3 \pm 1.03$ & 0.017 \\
\hline Triglyceride (mmol/L) & $2.0 \pm 1.54$ & $2.2 \pm 1.78$ & $1.7 \pm 0.97$ & $<0.001$ \\
\hline High density lipoprotein (mmol/L) & $1.5 \pm 0.36$ & $1.4 \pm 0.37$ & $1.5 \pm 0.35$ & $<0.001$ \\
\hline Low density lipoprotein ( $\mathrm{mmol} / \mathrm{L})$ & $3.0 \pm 1.02$ & $3.0 \pm 1.08$ & $3.0 \pm 0.91$ & 0.727 \\
\hline Diabetes (\%) & $94(5.7)$ & $46(4.4)$ & $48(8.1)$ & 0.003 \\
\hline Obesity (\%) & 252(15.4) & 176(16.9) & $76(12.7)$ & 0.027 \\
\hline
\end{tabular}

$\mathrm{BMI}=$ Body Mass Index, $\mathrm{BSA}=$ Body Surface Area, SBP = Systolic Blood Pressure, DBP = Diastolic Blood, $\mathrm{PP}=$ Pulse Pressure, MAP = Mean Arterial Blood Pressure

(3) Eccentric hypertrophy: LVMI was increased and RWT was < 0.43;

(4) Concentric remodeling: LVMI was normal and RWT was $\geq 0.43$.

\section{Statistical analysis}

Data are reported as mean \pm standard deviation (SD) for continuous variables and as frequency for categorical variables. Differences in continuous variables between two groups were compared with a Student t-test and differences in categorical variables were measured with a chi-square test. Differences between multiple groups were performed by analysis of variance (ANOVA). Logistic regression was used to calculate odds ratios (ORs) and their 95\% confidence intervals (CIs). Potential confounders were adjusted. A 2-tailed value of $\mathrm{P}<0.05$ was considered significant. Analyses were performed with SPSS 11.0 (SPSS Inc, Chicago, USA) for Windows (Microsoft Corp, Redmond, USA). The authors had full access to the data and take full responsibility for its integrity.

\section{Results}

Clinical and echocardiographic characteristics of untreated hypertensive population

A total of 1641 untreated hypertensive patients (1044 males and 597 females) with integrated clinical and echocardiographic data enrolled in the present study (Table 1 and Table 2).

LVIDD as well as PWTd were larger in men than in women, so did LV mass $(158.1 \pm 48.04 \mathrm{~g}$ vs. $142.5 \pm$ $41.69 \mathrm{~g}, \mathrm{P}<0.001)$. The trend was opposite after indexed by height ${ }^{2.7}(37.8 \pm 12.24$ vs. $42.0 \pm 12.79, \mathrm{P}<0.001)$, and by BSA $(83.5 \pm 25.13$ vs. $86.2 \pm 23.84, \mathrm{P}=0.027)$. Moreover, RWT was higher in women, but this difference did not attain statistical significance.

Table 2 Echocardiographic characteristics of 1641 untreated hypertensive patients

\begin{tabular}{|c|c|c|c|c|}
\hline Variables & Whole group $(n=1641)$ & Male $(n=1044)$ & Female $(n=597)$ & $\mathrm{p}$ value \\
\hline IVSd (mm) & $10.6 \pm 2.14$ & $10.5 \pm 2.20$ & $10.7 \pm 2.03$ & 0.053 \\
\hline PWTd (mm) & $9.4 \pm 1.54$ & $9.5 \pm 1.46$ & $9.1 \pm 1.64$ & $<0.001$ \\
\hline LVIDD (mm) & $44.4 \pm 5.25$ & $45.3 \pm 4.97$ & $42.9 \pm 5.37$ & $<0.001$ \\
\hline LV mass $(g)$ & $152.5 \pm 46.43$ & $158.1 \pm 48.04$ & $142.5 \pm 41.69$ & $<0.001$ \\
\hline $\operatorname{LVMI}-B S A\left(g / \mathrm{m}^{2}\right)$ & $84.5 \pm 24.70$ & $83.5 \pm 25.13$ & $86.2 \pm 23.84$ & 0.027 \\
\hline LVMI-height $^{2.7}\left(\mathrm{~g} / \mathrm{m}^{2.7}\right)$ & $39.4 \pm 12.60$ & $37.8 \pm 12.24$ & $42.0 \pm 12.79$ & $<0.001$ \\
\hline $\mathrm{RWT}(\mathrm{cm})$ & $0.43 \pm 0.092$ & $0.43 \pm 0.085$ & $0.44 \pm 0.102$ & 0.117 \\
\hline
\end{tabular}

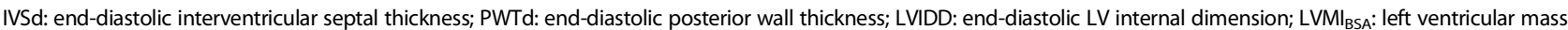
index divided by body mass index; LVMI ${ }_{\mathrm{h} 2.7}$ : left ventricular mass index divided by height ${ }^{2.7}$; RWT: relative wall thickness. 


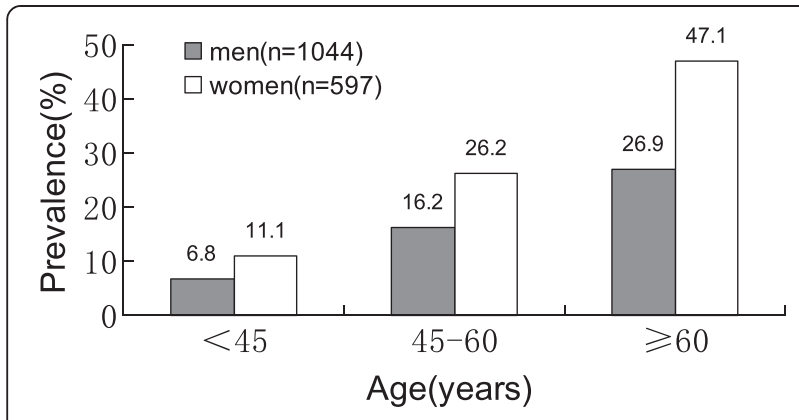

Figure 1 Prevalence of left ventricular hypertrophy (LVH) in different age and sex groups. The prevalence was much higher in women than in men in the age groups of $45-60$ and $\geq 60(p<0.01)$, and increasing with ageing.

Prevalence of LVH in untreated hypertensive population Of 1641 untreated hypertensive patients, 20.2\% ( $\mathrm{n}=332)$ was found to be $\mathrm{LVH}, 14.2 \%$ in men and $30.8 \%$ in women respectively. Sex-specific prevalence of LVH increased with ageing (Figure 1).

\section{The distribution of LV geometric patterns}

The total distribution of LV geometric patterns was concentric hypertrophy (11.1\%), eccentric hypertrophy (9.1\%), concentric remodeling (34.9\%) and normal geometric (44.9\%). Concentric remodeling was the most common abnormal LV geometric pattern in men (35.9\%), also, in women (33.0\%). The LV geometric abnormality increased steadily with ageing (from $43.8 \%$ to $71.0 \%$ ) (Table 3 ).

The risk factors of LVH in untreated hypertensive patients After adjusted for age, sex, systolic blood pressure, diastolic blood pressure, body mass index, cholesterol, triglyceride, high density lipoprotein cholesterol, low density lipoprotein cholesterol, smoking history, drinking history, history of diabetes, the following risk factors were identified by using Logistic regression model for confounders: age, female, SBP, BMI (Table 4).

The risk factors of abnormal LV geometric patterns in untreated hypertensive patients

After adjusted for age, sex, systolic blood pressure, diastolic blood pressure, body mass index, cholesterol, triglyceride, high density lipoprotein cholesterol, low density lipoprotein cholesterol, smoking history, drinking history, history of diabetes by using Logistic regression model for confounders, the risk factor of concentric remodeling was only age. The risk factors of concentric hypertrophy were age, female, SBP, BMI. The risk factors of eccentric hypertrophy were age, female, SBP, BMI, and high density lipoprotein and drinking history was found as protective factors for eccentric hypertrophy (Table 5).

\section{Discussion}

In the present study, the prevalence of LVH was $20.2 \%$ in the untreated hypertensive patients, while the prevalence of echocardiographic LVH was $42.8 \%$ among communitybased hypertensive population previously reported by our group [21]. In other studies, the prevalence of LVH in untreated hypertensive cohorts was quite different, from 19\% to $48 \%[18,22,23]$. The distribution of abnormal LV geometric patterns was $34.9 \%, 11.1 \%$ and $9.1 \%$ for concentric remodeling, concentric hypertrophy and eccentric hypertrophy in this study, respectively, while our group found the distribution was shown to be $24.7 \%, 22.6 \%, 20.2 \%$ respectively in hypertensive patients [21]. Concentric remodeling was the most prevalent type of abnormal LV geometry in both sexes. Concentric hypertrophy, a LV geometric pattern related to a worse CV prognosis [24,25], was more prevalent than eccentric hypertrophy, while lots of studies had come to the opposite conclusion [26-30]. The variation might result from the differences in age, gender, geographical region, diagnostic criteria, and risk factors.

It is worth noting that female was strongly associated with the prevalence of LVH and abnormal LV geometry

Table 3 The distribution of LV geometry patterns

\begin{tabular}{cccccc}
\hline Subgroup & $\begin{array}{c}\text { Normal geometry } \\
{[\boldsymbol{n}(\%)]}\end{array}$ & $\begin{array}{c}\text { Concentric remodeling } \\
{[\boldsymbol{n}(\%)]}\end{array}$ & $\begin{array}{c}\text { Concentric hypertrophy } \\
{[\boldsymbol{n}(\%)]}\end{array}$ & $\begin{array}{c}\text { Eccentric hypertrophy } \\
{[\boldsymbol{n}(\%)]}\end{array}$ & $\begin{array}{c}\text { Abnormal geometry } \\
{[\boldsymbol{n}(\%)]}\end{array}$ \\
\hline Sex & & & & & \\
Male & $521(49.9)$ & $375(35.9)$ & $74(7.1)$ & $74(7.1)$ & $523(50.1)$ \\
$\quad$ Female & $216(36.2)$ & $197(33.0)$ & $108(18.1)$ & $76(12.7)$ & $381(63.8)$ \\
$\begin{array}{l}\text { Age group } \\
\text { (years) }\end{array}$ & & & & & \\
$\quad \mathbf{4 5}$ & $305(56.2)$ & $197(36.3)$ & $20(3.7)$ & $21(3.9)$ & $238(43.8)$ \\
$\mathbf{4 5 - 6 0}$ & $317(45.2)$ & $241(34.4)$ & $75(10.7)$ & $68(9.7)$ & $384(54.8)$ \\
$\mathbf{2 6 0}$ & $115(29.0)$ & $134(33.8)$ & $87(21.9)$ & $61(15.4)$ & $282(71.0)$ \\
Total & $737(44.9)$ & $572(34.9)$ & $182(11.1)$ & $150(9.1)$ & $904(55.1)$ \\
\hline
\end{tabular}


Table 4 The risk factors of $\mathrm{LVH}$

\begin{tabular}{|c|c|c|c|}
\hline Variables & Odds ratio & $95 \% \mathrm{Cl}$ & $\mathbf{P}$ \\
\hline Age,year & 1.06 & $1.05-1.07$ & $<0.001$ \\
\hline Sex $(0=$ male, $1=$ female $)$ & 1.94 & $1.38-2.74$ & $<0.001$ \\
\hline $\mathrm{SBP}, \mathrm{mmHg}$ & 1.02 & $1.01-1.03$ & $<0.001$ \\
\hline $\mathrm{BMI}, \mathrm{kg} / \mathrm{m}^{2}$ & 1.19 & $1.14-1.24$ & $<0.001$ \\
\hline Cholesterol, $\mathrm{mmol} / \mathrm{L}$ & 0.876 & $0.759-1.010$ & 0.069 \\
\hline $\mathrm{HDL}, \mathrm{mmol} / \mathrm{L}$ & 0.66 & $0.42-1.05$ & 0.079 \\
\hline Drinking history ( $0=$ no, $1=$ yes $)$ & 0.69 & $0.47-1.02$ & 0.060 \\
\hline
\end{tabular}

Odds ratio was relative to no LVH. Adjusted for age, sex, systolic blood pressure, diastolic blood pressure, body mass index, cholesterol, triglyceride, high density lipoprotein cholesterol, low density lipoprotein cholesterol, smoking history, drinking history, history of diabetes. $P$ value for variables to enter or stay in the model was set at $<0.10$. $\mathrm{Cl}$, confidential interval.

in this study. This is in line with the majority of reports [31,32], as well as our previous study [21].

Ageing was also related with increased prevalence of LVH and abnormal LV geometry in untreated patients. These data were in line with our previous study [21]. De Simone et al. [33]. Have also reported that, in both normotensive and hypertensive patients, left ventricle mass steadily increases with age. The Bogalusa Heart Study indicates that age-related increase in left ventricular mass could be partially interpreted by changes in body size and in BP [34]. Due to the aging of general population in China, it demonstrated that the incidence of LVH would increase. Also, both SBP and BMI were associated with LVH after adjusted for other risk factors, consistented with the result of published studies $[32,35]$.

Furthermore, a further aspect of our study was that maybe low high density lipoprotein was associated with higher prevalence of eccentric hypertrophy after adjusted for other risk factors.

The advantages of the study is that, this is a good community-based survey design, the routine ascertainment of $\mathrm{LVH}$, and the definition of risk factors, survey data and echocardiography, which are similar to other well-known community-based studies.

In addition, another aspect of the present study deserves to be briefly discussed. A remarkable portion of untreated hypertensive patients enrolled in this study have had the manifestation of cardiac damage such as $\mathrm{LVH}$, this suggests that primary prevention of cardiovascular disease is extremely crucial and claims for raising awareness of hypertensive status and controling risk factors for cardiovascular disease.

Several limitations applied to our study. First, our findings are not fully applicable to Han Chinese, as our samples comprised untreated hypertensive residents in the northern region of China. Second, the cross-sectional nature of this study limits the prediction of abnormal LV geometric patterns on cardiovascular and cerebrovascular events, which should be confirmed with a prospective study.

\section{Conclusions}

Our study indicates that, in untreated hypertensive patients, $\mathrm{LVH}$ and abnormal LV geometric patterns is a predilection for female and the prevalence of LVH and abnormal LV geometric patterns increased with age.

Age, female, SBP, BMI are the major risk factors for LVH and abnormal LV geometric patterns. Also, low high density lipoprotein maybe has a positive effect on LVH.

Even though improved diagnosis and treatment of hypertension recent years, primary prevention of cardiovascular (CV) disease is extremely crucial. To effectively reducing of $\mathrm{CV}$ complications, it is of utmost importance that not only weight and BP control but also improving the awareness rate of hypertension in China and the risk factors of CV complications.

\section{Abbreviations}

LV geometry: Left ventricular geometry; LVH: Left ventricular hypertrophy; LVM: Left ventricular mass; LVMI: Left ventricular mass index; IVSd: Septal wall thickness at end diastole; PWTd: Posterior wall thickness at end diastole; LVIDD: Left ventricular end-diastolic diameter; RWT: Relative wall thickness;

Table 5 The risk factors of abnormal left ventricular geometric patterns

\begin{tabular}{|c|c|c|c|c|c|c|c|c|c|}
\hline \multirow[t]{2}{*}{ Variables } & \multicolumn{3}{|c|}{ Concentric remodeling } & \multicolumn{3}{|c|}{ Concentric hypertrophy } & \multicolumn{3}{|c|}{ Eccentric hypertrophy } \\
\hline & Odds ratio & $95 \% \mathrm{Cl}$ & $\mathbf{P}$ & Odds ratio & $95 \% \mathrm{Cl}$ & $\mathbf{P}$ & Odds ratio & $95 \% \mathrm{Cl}$ & $P$ \\
\hline Age,year & 1.02 & $1.01-1.03$ & $<0.001$ & 1.07 & $1.05-1.09$ & $<0.001$ & 1.06 & $1.04-1.08$ & $<0.001$ \\
\hline \multicolumn{10}{|l|}{ Sex } \\
\hline ( $0=$ male, $1=$ female $)$ & 1.20 & $0.93-1.55$ & 0.158 & 2.51 & $1.70-3.71$ & $<0.001$ & 1.76 & $1.07-2.87$ & 0.025 \\
\hline $\mathrm{SBP}, \mathrm{mmHg}$ & 1.00 & $0.99-1.01$ & 0.615 & 1.03 & $1.02-1.04$ & $<0.001$ & 1.02 & $1.00-1.03$ & 0.020 \\
\hline BMI, $\mathrm{kg} / \mathrm{m}^{2}$ & 0.99 & $0.95-1.03$ & 0.567 & 1.17 & $1.11-1.24$ & $<0.001$ & 1.21 & $1.14-1.29$ & $<0.001$ \\
\hline $\mathrm{HDL}, \mathrm{mmol} / \mathrm{L}$ & 0.92 & $0.64-1.31$ & 0.651 & 0.95 & $0.54-1.69$ & 0.865 & 0.37 & $0.18-0.73$ & 0.004 \\
\hline Drinking history $(0=$ no, $1=$ yes $)$ & 1.00 & $0.75-1.33$ & 0.974 & 0.76 & $0.44-1.31$ & 0.321 & 0.53 & $0.31-0.94$ & 0.028 \\
\hline
\end{tabular}

Odds ratio was relative to normal geometry pattern. Adjusted for age, sex, systolic blood pressure, diastolic blood pressure, body mass index, cholesterol, triglyceride, high density lipoprotein, low density lipoprotein, smoking history, drinking history, history of diabetes. $P$ value for variables to enter or stay in the model was set at $<0.10$. Cl, confidential interval. 
SBP: Systolic blood pressure; DBP: Diastolic blood pressure; BSA: Body surface area; CV: Cardiovascular.

\section{Competing interests}

The authors declare that they have no competing interests.

\section{Authors' contributions}

HL: first author of this work, has made substantial contributions to the conception and design of the paper and the analysis and interpretation of data, and been involved in drafting the manuscript. FP, LYS, JZC, XYZ, CNZ, $J B L$ have participated in patient evaluations, data collection, and report writing. KS: was involved in statistical analysis. CSX has made contributions to the conception and design of the paper, and been involved in revising the manuscript. RTH: was involved in supervisory role in study concept, manuscript writing and critical review of the work at all stages. All authors read and approved the final manuscript.

\section{Acknowledgements}

This work was supported by the Key Project in the National Science \& Technology Pillar Program during the 12th 5-Year Plan Period (2011BAl11B04 to Dr Hui Rutai and Dr Xiao Chuanshi).

\section{Author details}

'Department of Cardiology, The First Hospital Affiliated to Shanxi Medical University, 85 Jiefang South Road, Taiyuan City, Shanxi Province 030001, China. ${ }^{2}$ Sino-German Laboratory for Molecular Medicine, State Key Laboratory of Cardiovascular Disease, Fuwai Hospital, National Center for Cardiovascular Diseases, Chinese Academy of Medical Sciences and Peking Union Medical College, 167 Beilishilu, Beijing 100037, China. ${ }^{3}$ Department of Cardiology, Bethune First Hospital of Jilin University, 71 Xinmin Street, Changchun City, Jilin Province 130021, PR China.

Received: 16 December 2013 Accepted: 29 September 2014 Published: 4 October 2014

\section{References}

1. Levy D, Anderson KM, Savage DD, Kannel WB, Christiansen JC, Castelli WP: Echocardiographically detected left ventricular hypertrophy: prevalence and risk factors. The Framingham Heart Study. Ann Intern Med 1988, 108(1):7-13.

2. Kannel WB, Doyle JT, McNamara PM, Quickenton P, Gordon T: Precursors of sudden coronary death. Factors related to the incidence of sudden death. Circulation 1975, 51(4):606-613.

3. McLenachan JM, Henderson $\mathrm{E}_{1}$ Morris $\mathrm{Kl}$, Dargie HJ: Ventricular arrhythmias in patients with hypertensive left ventricular hypertrophy. $N$ Engl J Med 1987, 317(13):787-792.

4. Dunn FG, Pringle SD: Left ventricular hypertrophy and myocardial ischemia in systemic hypertension. Am J Cardio/ 1987, 60(17):191-221.

5. Liao Y, Cooper RS, McGee DL, Mensah GA, Ghali JK: The relative effects of left ventricular hypertrophy, coronary artery disease, and ventricular dysfunction on survival among black adults. JAMA 1995, 273(20):1592-1597.

6. Kannel WB, Castelli WP, McNamara PM, McKee PA, Feinleib M: Role of blood pressure in the development of congestive heart failure. The Framingham study. N Engl J Med 1972, 287(16):781-787.

7. Fox ER, Alnabhan N, Penman AD, Butler KR, Taylor HA Jr, Skelton TN, Mosley $\mathrm{TH}$ Jr: Echocardiographic left ventricular mass index predicts incident stroke in African Americans: Atherosclerosis Risk in Communities (ARIC) Study. Stroke 2007, 38(10):2686-2691.

8. Leese PJ, Viera AJ, Hinderliter AL, Stearns SC: Cost-effectiveness of electrocardiography vs. electrocardiography plus limited echocardiography to diagnose LVH in young, newly identified, hypertensives. Am J Hypertens 2010, 23(6):592-598.

9. Ganau A, Devereux RB, Roman MJ, de Simone G, Pickering TG, Saba PS, Vargiu P, Simongini I, Laragh JH: Patterns of left ventricular hypertrophy and geometric remodeling in essential hypertension. J Am Coll Cardiol 1992, 19(7):1550-1558.

10. Koren MJ, Devereux RB, Casale PN, Savage DD, Laragh JH: Relation of left ventricular mass and geometry to morbidity and mortality in uncomplicated essential hypertension. Ann Intern Med 1991, 114(5):345-352.
11. Krumholz HM, Larson M, Levy D: Prognosis of left ventricular geometric patterns in the Framingham Heart Study. J Am Coll Cardiol 1995, 25(4):879-884

12. Di Tullio MR, Zwas DR, Sacco RL, Sciacca RR, Homma S: Left ventricular mass and geometry and the risk of ischemic stroke. Stroke 2003, 34(10):2380-2384.

13. Fox E, Taylor H, Andrew M, Han H, Mohamed E, Garrison R, Skelton T: Body mass index and blood pressure influences on left ventricular mass and geometry in African Americans: The Atherosclerotic Risk In Communities (ARIC) Study. Hypertension 2004, 44(1):55-60.

14. Lorber R, Gidding SS, Daviglus ML, Colangelo LA, Liu K, Gardin JM: Influence of systolic blood pressure and body mass index on left ventricular structure in healthy African-American and white young adults: the CARDIA study. J Am Coll Cardiol 2003, 41(6):955-960.

15. Cheitlin MD, Armstrong WF, Aurigemma GP, Beller GA, Bierman FZ, Davis $J$, Douglas PS, Faxon DP, Gillam LD, Kimball TR, Kussmaul WG, Pearlman AS, Philbrick JT, Rakowski H, Thys DM, Antman EM, Smith SC Jr, Alpert JS, Gregoratos G, Anderson JL, Hiratzka LF, Faxon DP, Hunt SA, Fuster V, Jacobs AK, Gibbons RJ, Russell RO, ACC; AHA; ASE: ACC/AHA/ASE 2003 guideline update for the clinical application of echocardiography: summary article: a report of the American College of Cardiology/American Heart Association Task Force on Practice Guidelines (ACC/AHA/ASE Committee to Update the 1997 Guidelines for the Clinical Application of Echocardiography). Circulation 2003, 108(9):1146-1162.

16. Devereux RB, Alonso DR, Lutas EM, Gottlieb GJ, Campo E, Sachs I, Reichek N: Echocardiographic assessment of left ventricular hypertrophy: comparison to necropsy findings. Am J Cardiol 1986, 57(6):450-458.

17. Du Bois D, Du Bois EF: A formula to estimate the approximate surface area if height and weight be known. 1916. Nutrition 1989, 5(5):303-311. discussion 312-303.

18. de Simone G, Izzo R, Chinali M, De Marco M, Casalnuovo G, Rozza F, Girfoglio D, lovino GL, Trimarco B, De Luca N: Does information on systolic and diastolic function improve prediction of a cardiovascular event by left ventricular hypertrophy in arterial hypertension? Hypertension 2010, 56(1):99-104.

19. Li L, Shigematsu Y, Hamada M, Hiwada K: Relative wall thickness is an independent predictor of left ventricular systolic and diastolic dysfunctions in essential hypertension. Hypertens Res 2001, 24(5):493-499.

20. Gerdts E, Cramariuc D, de Simone G, Wachtell K, Dahlof B, Devereux RB: Impact of left ventricular geometry on prognosis in hypertensive patients with left ventricular hypertrophy (the LIFE study). Eur J Echocardiogr 2008, 9(6):809-815.

21. Wang SX, Xue H, Zou YB, Sun K, Fu CY, Wang H, Hui RT: Prevalence and risk factors for left ventricular hypertrophy and left ventricular geometric abnormality in the patients with hypertension among Han Chinese. Chin Med J (Engl) 2012, 125(1):21-26.

22. Schillaci G, Pirro M, Pucci G, Mannarino MR, Gemelli F, Siepi D, Vaudo G, Mannarino E: Different impact of the metabolic syndrome on left ventricular structure and function in hypertensive men and women. Hypertension 2006, 47(5):881-886.

23. Mule G, Cusimano P, Nardi E, Cottone S, Geraci C, Palermo A, Costanzo M, Foraci AC, Cerasola G: Relationships between metabolic syndrome and left ventricular mass in hypertensive patients: does sex matter? J Hum Hypertens 2008, 22(11):788-795.

24. Muiesan ML, Salvetti M, Monteduro C, Bonzi B, Paini A, Viola S, Poisa P, Rizzoni D, Castellano M, Agabiti-Rosei E: Left ventricular concentric geometry during treatment adversely affects cardiovascular prognosis in hypertensive patients. Hypertension 2004, 43(4):731-738.

25. Milani RV, Lavie CJ, Mehra MR, Ventura HO, Kurtz JD, Messerli FH: Left ventricular geometry and survival in patients with normal left ventricular ejection fraction. Am J Cardiol 2006, 97(7):959-963.

26. Saba MM, Ibrahim MM, Rizk HH: Gender and the relationship between resting heart rate and left ventricular geometry. J Hypertens 2001, 19(3):367-373.

27. Cipriano C, Gosse P, Bemurat L, Mas D, Lemetayer P, N'Tela G, Clementy J: Prognostic value of left ventricular mass and its evolution during treatment in the Bordeaux cohort of hypertensive patients. Am J Hypertens 2001, 14(6 Pt 1):524-529.

28. Cuspidi C, Ambrosioni E, Mancia G, Pessina AC, Trimarco B, Zanchetti A: Role of echocardiography and carotid ultrasonography in stratifying risk in patients with essential hypertension: the assessment of prognostic risk observational survey. J Hypertens 2002, 20(7):1307-1314. 
29. Glorioso N, Filigheddu F, Parpaglia PP, Soro A, Troffa C, Argiolas G, Mulatero P: 11beta-Hydroxysteroid dehydrogenase type 2 activity is associated with left ventricular mass in essential hypertension. Eur Heart J 2005, 26(5):498-504.

30. Cuspidi C, Giudici V, Lonati L, Sala C, Valerio C, Mancia G: Left ventricular hypertrophy detection and body mass index in essential hypertension. Blood Press 2010, 19(6):337-343.

31. Gerdts E, Okin PM, de Simone G, Cramariuc D, Wachtell K, Boman K, Devereux RB: Gender differences in left ventricular structure and function during antihypertensive treatment: the Losartan Intervention for Endpoint Reduction in Hypertension Study. Hypertension 2008, 51(4):1109-1114

32. Conrady AO, Rudomanov OG, Zaharov DV, Krutikov AN, Vahrameeva NV, Yakovleva OI, Alexeeva NP, Shlyakhto EV: Prevalence and determinants of left ventricular hypertrophy and remodelling patterns in hypertensive patients: the St. Petersburg study. Blood Press 2004, 13(2):101-109.

33. de Simone G, Daniels SR, Kimball TR, Roman MJ, Romano C, Chinali M, Galderisi M, Devereux RB: Evaluation of concentric left ventricular geometry in humans: evidence for age-related systematic underestimation. Hypertension 2005, 45(1):64-68.

34. Burke GL, Arcilla RA, Culpepper WS, Webber LS, Chiang YK, Berenson GS: Blood pressure and echocardiographic measures in children: the Bogalusa Heart Study. Circulation 1987, 75(1):106-114.

35. Kuch B, Hense HW, Gneiting B, Doring A, Muscholl M, Brockel U, Schunkert $\mathrm{H}$ : Body composition and prevalence of left ventricular hypertrophy. Circulation 2000, 102(4):405-410.

doi:10.1186/1471-2261-14-136

Cite this article as: Li et al:: Prevalence and risk factors of abnormal left ventricular geometrical patterns in untreated hypertensive patients.

\section{Submit your next manuscript to BioMed Central and take full advantage of:}

- Convenient online submission

- Thorough peer review

- No space constraints or color figure charges

- Immediate publication on acceptance

- Inclusion in PubMed, CAS, Scopus and Google Scholar

- Research which is freely available for redistribution 